\title{
Finite element simulation of seawater intrusion into a quarry-site coastal aquifer, Kocaeli-Darıca, Turkey
}

\author{
Nurkan Karahanoglu $\cdot$ Vedat Doyuran
}

Abstract A numerical simulation has been carried out to investigate the effects of below-sea-level (b.s.l.) excavation on the raw material quality of a cement quarry in Turkey. The model simulates variations in the hydrodynamic and hydrogeochemical mechanisms in the coastal aquifer upon BSL excavation. In this context, behavior of the seawater intrusion zone, changes in water levels, and salt concentrations have been simulated. In the development of the model, previous geological and hydrogeological reports of the quarry site and the near vicinity have been considered. Eleven new wells (BH-1,...BH-11) have been drilled to reveal hydrogeological features of the area and also for periodical observations of the water levels and hydrogeochemical monitoring. These wells were utilized to develop and calibrate the model to the field conditions. Physical and hydrogeochemical parameters used in the model have been evaluated using available hydrogeological data, the field test results and the related literature. The model has been verified using the field observations. It is based on the virgin conditions of the aquifer as well as on the data for years 1990 and 2001. An average raw material production rate for the cement factory was considered during development of the model, and for making future predictions. Two alternative production scenarios have been considered and probable effects of abovesea-level (a.s.l.) and b.s.l. excavations on seawater intrusion into the aquifer have been studied. Future prediction studies are based on these two production scenarios that assume 43 years of total production (30 years of a.s.l. and 13 years of b.s.l. production) in the quarry. The first scenario, Scenario I, assumes

Received: 1 July 2002 / Accepted: 18 January 2003

Published online: 1 May 2003

(C) Springer-Verlag 2003

N. Karahanoglu $(\bowtie) \cdot$ V. Doyuran

Department of Geological Engineering,

Middle East Technical University, 06531 Ankara, Turkey

E-mail: nurkan@metu.edu.tr that starting from 2001, the next 30 years would be devoted only to ASL and then the remaining 13 years would be used for b.s.l. production. Scenario II, on the other hand, assumes simultaneous operations both at a.s.l. and b.s.l. levels for the next 43 years after 2001. Effects of b.s.l. production in the quarry site have been simulated accordingly, and seawater intrusion into the aquifer as well as water discharge rates have been predicted for $-10,-20$ and $-30 \mathrm{~m}$ production levels.

Keywords Seawater intrusion modeling BSL mining simulation

\section{Introduction}

Kocaeli-Darica (Turkey) Aslan Cement quarry is located at the south of Kocaeli Peninsula, approximately $5 \mathrm{~km}$ southwest of Gebze and $2.5 \mathrm{~km}$ west of Darica (Fig. 1). The quarry has been in operation since 1970s and it is now planned to be excavated below sea levels. In order to explore the possibility of below sea level (b.s.l.) quarrying research has been carried out to investigate the hydrogeological and hydrogeochemical conditions at the site, to estimate the amount of discharge from the pit, and also to determine the rate of advance of the salt water front during below sea level mining (Doyuran and others, 2001). In order to accomplish this task the studies were performed in two phases. In the first phase previous studies have been reviewed, the possibility of using previously opened boreholes has been researched, and a total of 11 boreholes have been drilled (1) to monitor groundwater levels in the wells, (2) to perform water pressure tests (WPT), and (3) to conduct hydrochemical observations and water sampling. During the second phase of the project, a finite element model was prepared to estimate the amount of water discharge from the pit and also to determine the rate of advance of the salt water front during b.s.l. mining. First, model calibration studies have been completed and then, considering different scenarios, the impact of quarrying operations on the hydrogeological and hydrochemical regime of the aquifer has been assessed. 


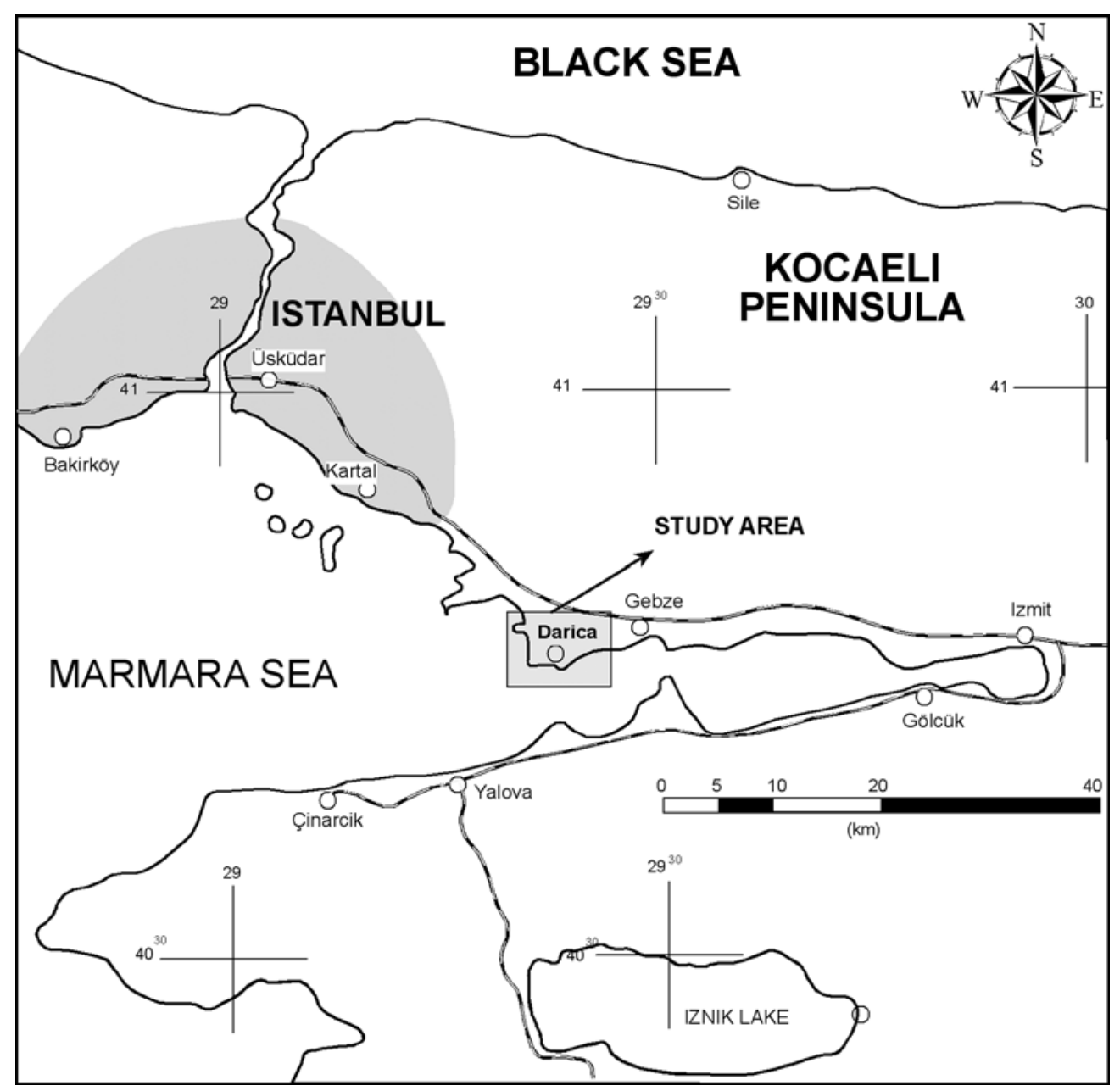

Fig. 1

Location map of the study area

Previous geological studies related with Kocaeli-Darıca Lafarge Aslan Cement raw material area were conducted by Erguvanl1 and others (1972) and MTA (1991). Gültekin (1983) also performed cement raw material investigation studies and provided detailed information about regional geology. Numerous boreholes opened for raw material reserve estimation and hydrogeological works also provided valuable data about subsurface geology. The geological map of the raw material area is periodically updated by Lafarge Aslan Cement.

MTA (1991) conducted research in the area to investigate hydrogeology of the quarry site and the near vicinity. Several boreholes were drilled in the area and pumping tests were performed to determine hydraulic conductivity, transmissivity and the storage coefficient values. Depths to water levels were recorded and Ghyben-Herzberg relation was applied to determine position of saltwater/freshwater interface. It was estimated that the interface was to be found at depths of 51.6 and $26 \mathrm{~m}$ (m.s.l) at distances of 125 and $83 \mathrm{~m}$ away from the shoreline, respectively.

Yeraltı Aramacilı (1994) conducted geophysical investigations at the quarry site to determine saltwater/freshwater interface and also to assess excavatability of the rocks. They prepared an iso-interface map for the site and determined depths to interface at different locations. Three discontinuities were located at the quarry site and it was concluded that, based on the results of geophysical survey, no saltwater wedge was expected from north towards south, due to southward dipping of the layers.

GEMMES (1997) developed a model for the quarry site to predict groundwater inflow rates and the migration of the saltwater front. For their study 6 pumping wells, 18 observation wells, and a trench extending parallel to the shoreline were opened. Based on pumping test results an iso-transmissivity contour map was prepared. The pumping tests performed at one well yielded a transmissivity value of $2.2 \times 10^{-3} \mathrm{~m}^{2} / \mathrm{s}$. Such high transmissivity value was attributed to the existence of fractures penetrated at depths $20-22 \mathrm{~m}$.

GEMMES (1997), using finite element method, prepared a flow and transport model. This model was calibrated in the quarry site along two E-W trending profiles, and then used for simulation of alternative scenarios. At the north profile, disregarding the concentration at $-30 \mathrm{~m}$, it is claimed that computed and observed concentration values show good agreement. The conductivity values assigned to the profiles were not the same throughout. In the west, within the first $75 \mathrm{~m}$, the hydraulic conductivity $(\mathrm{K})$ value was taken as ten times greater than that for the east. Thus, more saltwater intrusion is modeled in the west. The 
results of computations have shown that the computed values were greater than the observed values. The same model was applied to a quarry site, $125 \mathrm{~m}$ away from the shoreline and $-35 \mathrm{~m}$ deep, and steady-state conditions were reached at the end of 20 years. The model does not consider excavation in successive steps.

Seawater intrusion into coastal aquifers has been analytically and numerically investigated by several researchers since the study of Ghyben and Herzberg in the 1890s (Bear and Dagan 1964; Shamir and Dagan, 1971; Frind 1982; Reilly and Goodman 1985; Voss and Anderson 1993). Recent studies focus on complicated aquifer conditions and the intrusion problem has extensively been investigated (Croucher and O'Sullivan 1995; Emekli and others 1996; Huyakorn and others 1996; Sadeg and Karahanoğlu 2001).

\section{Hydrogeology}

\section{Water-bearing properties}

At the study area the carbonate rocks dominate the lithology. They are composed of limestones, dolomites and marls with occasional alternations of conglomerate, sandstone and claystones.

The primary porosity of the lithological unit of the study area is very low. The secondary porosity, controlled by joints, fractures, shear zones, etc., provides a certain amount of storage function. The marly limestone contains thin layers and/or lamina of claystones, which are also the main infilling material for the joints and fractures. No significant karstification is observed within marly limestones. Some iron oxide stained fracture zones may provide clues for limited water circulation. However, even in such zones no solution widening is noted. Due to small primary and secondary porosities, no significant amount of water storage may be expected within the sequence. Due to minimal porosities and small pore diameter, the permeability of the rocks is very low. The discontinuities, which provide secondary permeability to the rocks, may permit groundwater circulation.

The sedimentary sequence observed at the study area generally dip toward south and southeast. These thinto-medium thick-bedded carbonate rocks occasionally alternate with laminated claystones. Through undulating or broadly folded beds of the sequence no significant groundwater discharges are anticipated. Additionally, the apertures of the bedding planes are tight to very narrow, and they contain clayey infilling.

Systematic joint measurements yielded three joint sets: $\mathrm{N} 67^{\circ} \mathrm{E} / 75^{\circ} \mathrm{NW} ; \mathrm{N} 39^{\circ} \mathrm{W} / 71^{\circ} \mathrm{NE}$; and $\mathrm{N} 22^{\circ} \mathrm{E} / 90^{\circ}$. Their spacings are narrow to moderate, persistence is very low (bed confined), and apertures are tight to narrow. Main infilling is clayey soil and locally the joint surfaces contain iron oxide stains. Thus, the joints do not contribute significantly to groundwater circulation.

During field studies some shear zones and faults were observed at the working benches. The field measurements revealed that they generally trend $\mathrm{E}-\mathrm{W}$ and dip nearly vertically. The width of the shear zones range between 8 to $200 \mathrm{~mm}$ (moderate to very wide), their persistence exceeds $10 \mathrm{~m}$, and the infilling materials are clays, sands, and rarely breccia. The shear zones may be considered rather significant for groundwater circulation throughout the area.

During drilling of the boreholes, it is seen that the groundwater flow is mainly controlled by the shear zones. In the boreholes drilled by using air flush, localised water seepages are encountered and then the hole again progresses in dry conditions. The presence of iron oxide staining in the shear and/or highly fractured zones may be regarded as an indication of water circulation.

The results of water pressure tests conducted in $\mathrm{BH}-1-\mathrm{BH}-$ 4 show that the hydraulic conductivities range between $10^{-6}$ and $10^{-8} \mathrm{~m} / \mathrm{s}$, which are in very good agreement with those determined by MTA (1991) and GEMMES (1997). These values suggest that the aquifer is very poor. During b.s.l. mining activities the saltwater interface seems to be controlled by the shear zones.

\section{Groundwater level measurements}

In order to determine the position of the groundwater table the boreholes $\mathrm{BH}-1-\mathrm{BH}-11$ are equipped with PVC pipes and filters. In addition to these, some of the existing wells are also used for groundwater monitoring programs (Fig. 2). Table 1 summarizes the water level data. From the table it is seen that the water levels do not show regular patterns. In the wells located at the west platform the water level ranges between $0.3-0.7 \mathrm{~m}$, while $\mathrm{BH}-7$ and $\mathrm{BH}-8$ are practically dry. Toward east the water table progressively rises. During drilling of boreholes BH-6 (44 m), BH-7 (water+ foam circulation), BH-8 (dry), BH-9 (24 m), BH-10 (18 m) and $\mathrm{BH}-1$ (12 and $38 \mathrm{~m}$ ) water is encountered at depths indicated, and below these depths the wells again advanced within dry rocks. This suggests that local zones of saturation (perched aquifer) are also present above the fractured rock aquifer.

\section{Groundwater quality}

Electrical conductivity (EC) profile measurements were carried out in the waters of both existing wells (K1, K3, $\mathrm{K} 4, \mathrm{~K} 6$, and K7) and newly opened wells (BH-1, BH-2, and BH-3) in October 2000, January, March, May, July, and September 2001, covering dry and wet seasons, in order to determine the freshwater-saltwater extension in the groundwater. Chloride concentrations were also measured in the laboratory using water samples collected from different depths of the well $\mathrm{K} 3$ in October 2000. In addition, $\mathrm{H}_{2} \mathrm{O} \%$ and $\mathrm{Cl} \%$ measurements were conducted by the Aslan Cement Laboratory on the core samples, recovered from different depths of the wells $\mathrm{BH}-1, \mathrm{BH}-2, \mathrm{BH}-3$ and $\mathrm{BH}-4$. Observations show that freshwater-seawater mixing rates in the waters of the wells change with respect to vertical and horizontal location in the project area. Freshwater-seawater mixing interface is located closer to the surface in the wells that are located closer to sea whereas the interface location becomes relatively deeper in the wells located away from the shoreline. 


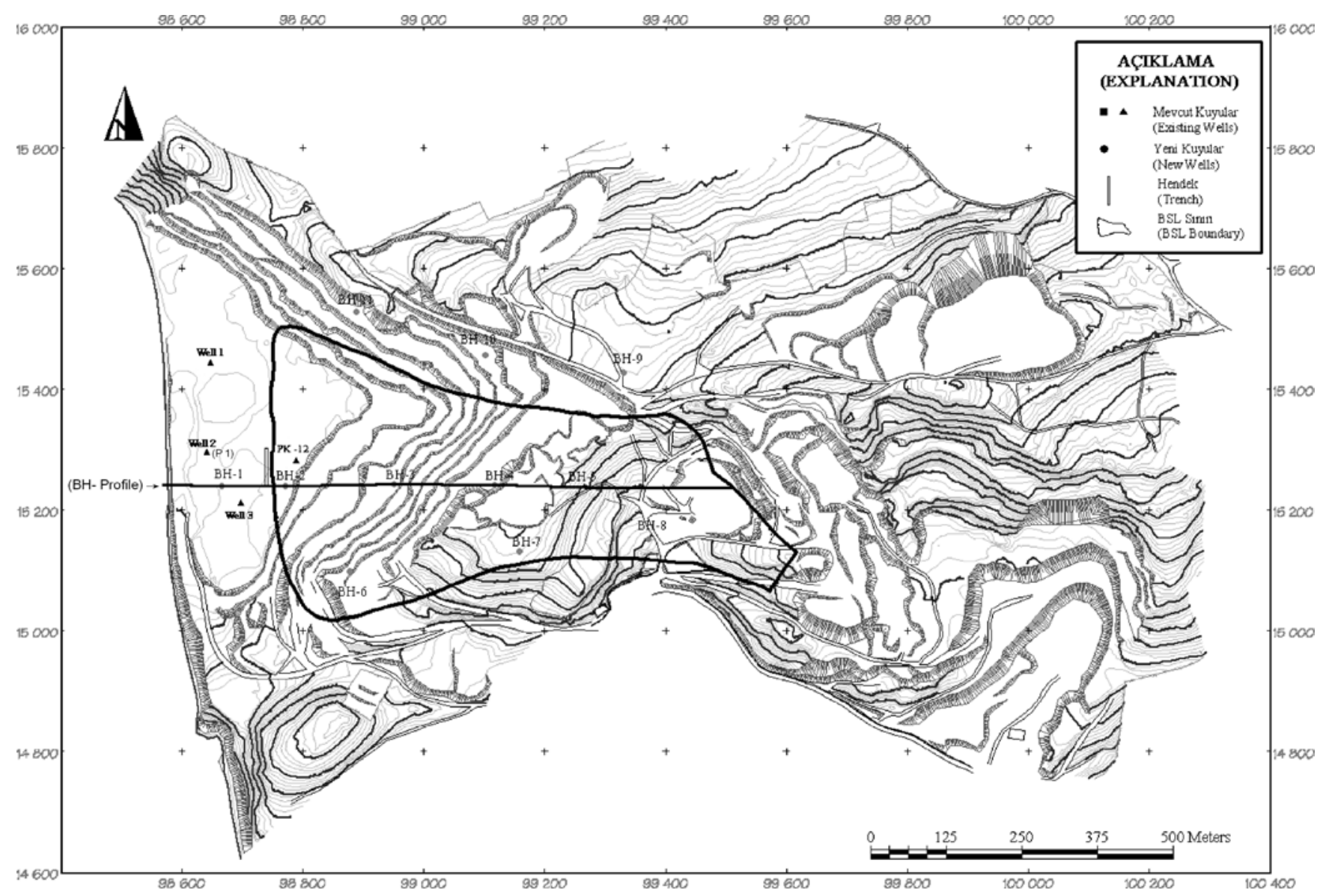

Fig. 2

Distribution of wells within the study area

Table 1

Groundwater level measurements

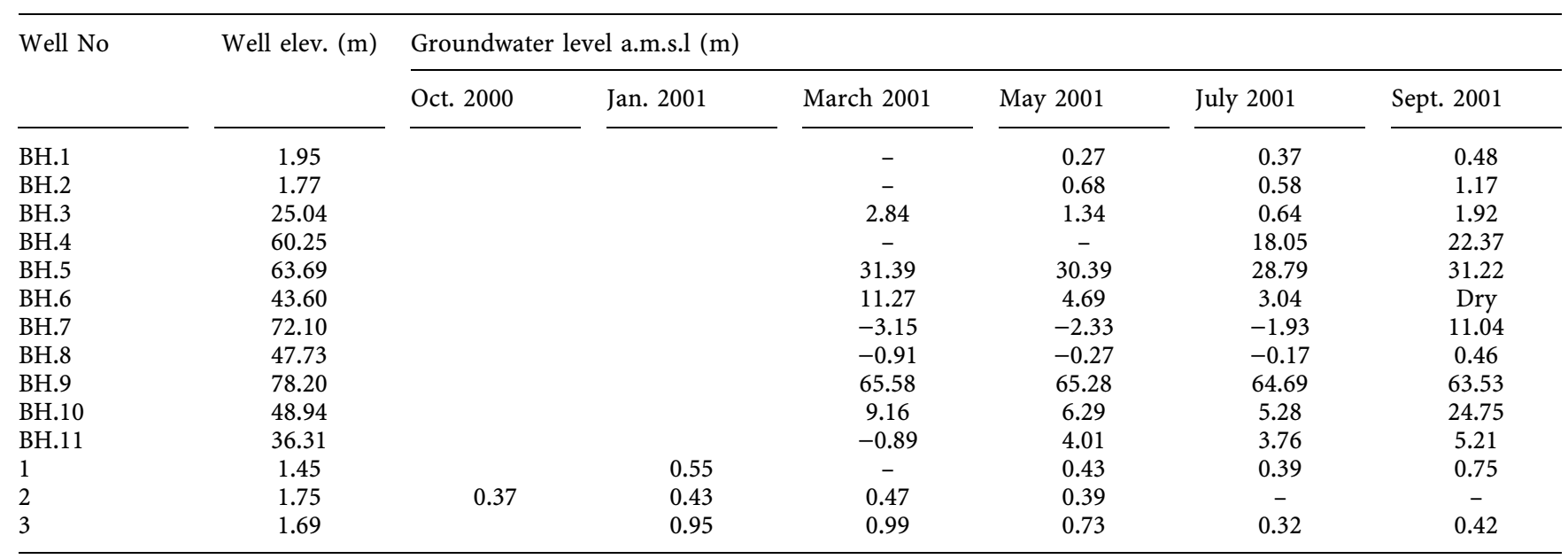

\section{Numerical model}

A two-dimensional numerical model (cross-sectional) was developed to simulate seawater intrusion into the aquifer, which is located along BH-1- BH-5 profile. The model, being $1,000 \mathrm{~m}$ long and $100 \mathrm{~m}$ deep, has 3,440 rectangular finite elements with 3,633 nodes (Fig. 3 ). The elements have $(5 \times 5 \mathrm{~m})$ dimensions in the first $710 \mathrm{~m}$ from the coast and then they become $(10 \times 5 \mathrm{~m})$ in the rest of the model to a distance of $1000 \mathrm{~m}$. The numerical model solves the flow equation and the density-dependent diffusion equation in a coupled manner (Voss 1984) and evaluates the unknown variables (pressure-heads and concentrations) at 3,633 nodal points and hence obtains 


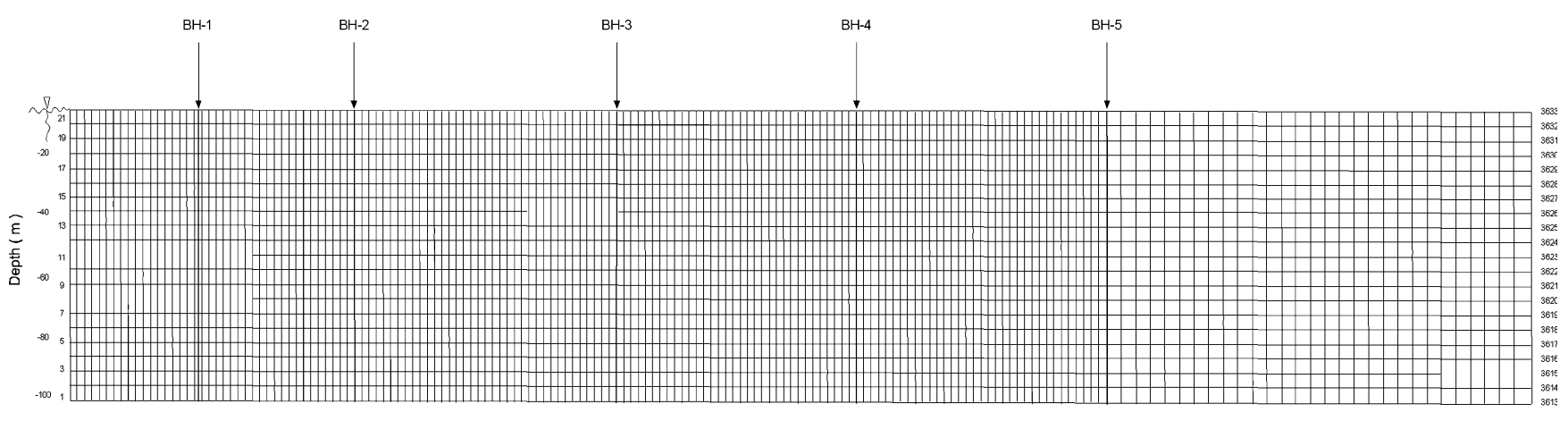

Distance from sea $(m)$

Fig. 3

Finite element mesh of the numerical model

Seawater Intrusion into the Aquifer Initial Conditions

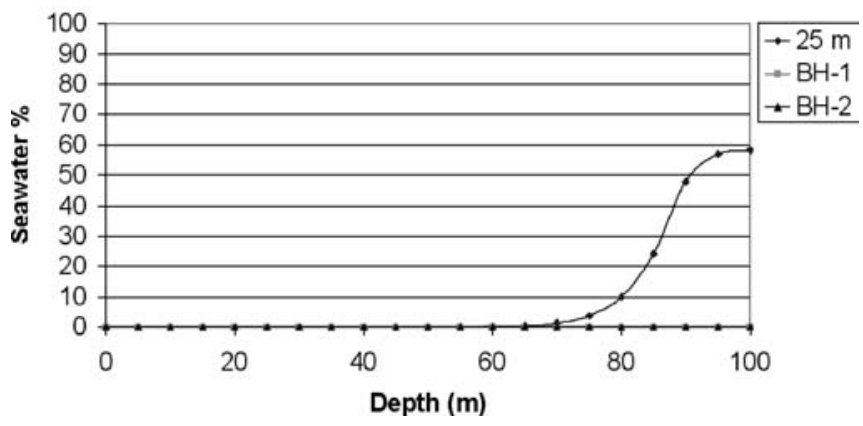

Fig. 4

Seawater intrusion into the aquifer under initial conditions (at locations of $25 \mathrm{~m}$ from the shoreline, $\mathrm{BH}-1$ and $\mathrm{BH}-2$ wells)

their distributions in the aquifer at the end of each solution step.

\section{Calibration of the model}

Calibration of the numerical model to field conditions has been accomplished in a time dependent (transient) manner using the historical background of the aquifer. Transient calibration (history matching) has been performed in three stages starting from the virgin conditions of the aquifer and its historical evolution during above sea level (a.s.l.) production in the quarry. In the first stage, the virgin condition of the aquifer was simulated using a transient-steady-state approach. At time zero, seawater begins to intrude into the aquifer (where there is no salt water initially) across the sea boundary. In this way the initial position of the interface is approached by progressive intrusion of seawater. This mechanism is simulated by transient steady-state calibration and the transient solution is continued until a negligible difference is detected between successive time steps. There is not any record found in the archives about initial conditions of the aquifer in terms of the water levels and the seawater concentrations. For this reason initial conditions of the aquifer were achieved using assumed values of the water levels and the equilibrium was obtained through a transient-steady-state calibration (Fig. 4).
Seawater Intrusion into the Aquifer Year 1990

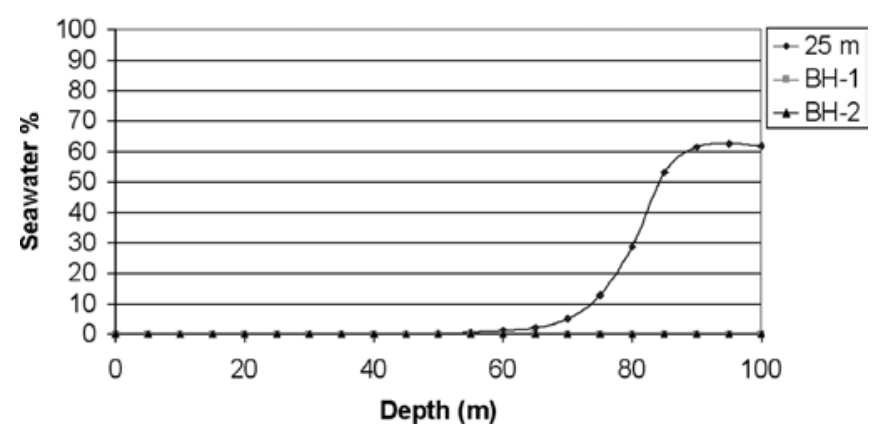

Fig. 5

Seawater intrusion into the aquifer in the year 1990 (at locations of $25 \mathrm{~m}$ from the shoreline, $\mathrm{BH}-1$ and $\mathrm{BH}-2$ wells)

Records of water levels and variation of concentration with respect to distance and depth were utilized in the calibration runs. It is a fact that such coupled mechanisms would require calibration study to be completed for both of the variables to perform a successful simulation study. This concept was used in the calibration study and distribution of the physical and the hydrogeochemical parameters as well as the boundary conditions were obtained to be used in future simulations. The model has estimated groundwater levels and the concentrations for the year 1990 by using the initial values of the variables at the end of first step of the calibration. The computed (estimated) values of the variables are compared with the observed water levels at wells P1 (static level $1.29 \mathrm{~m}$ ) and PK12 (static level $7.95 \mathrm{~m}$ ) that were located at the first platform (MTA, 1991). MTA (1991) reported that there was no indication of seawater intrusion in these wells and they have estimated depths to the interface by using Ghyben-Herzberg relation. In the calibration study it is assumed that neither the water levels nor the concentrations, and hence position of the saltwater wedge, have changed before the first platform was formed. It is thought that the quarried zone was far above the steady state water levels and excavations had not reached the water table in the aquifer. It is clear that the water levels in 1990 have been reached after the platform was formed and then the 
Table 2

Observed and computed water levels along $\mathrm{BH}$ profile (result of calibration)

\begin{tabular}{|c|c|c|c|c|c|c|c|c|}
\hline Well No. & $\begin{array}{c}\text { Dist. from } \\
\text { shoreline }(\mathrm{m})\end{array}$ & $\begin{array}{l}\text { Computed } \\
\text { Initial value } \\
(\mathrm{m})\end{array}$ & $\begin{array}{c}\text { Computed } \\
1990\end{array}$ & $\begin{array}{l}\text { Observed } \\
1990\end{array}$ & $\begin{array}{l}\text { Computed } \\
2001\end{array}$ & $\begin{array}{l}\text { Observed } \\
\text { May } 01\end{array}$ & $\begin{array}{l}\text { Observed } \\
\text { July } 01\end{array}$ & $\begin{array}{l}\text { Observed } \\
\text { Average }\end{array}$ \\
\hline BH-1 & 88.5 & 2.08 & 1.1 & $1.29^{\mathrm{a}}$ & 0.27 & 0.27 & 0.37 & 0.32 \\
\hline BH-2 & 195 & 9.19 & 7.95 & $7.95^{\mathrm{b}}$ & 0.3 & 0.68 & 0.58 & 0.63 \\
\hline BH-3 & 374.8 & 24.99 & 22.39 & - & 1.03 & 1.34 & 0.64 & 0.99 \\
\hline
\end{tabular}

${ }^{\mathrm{a} O b s e r v e d}$ at well $\mathrm{P} 1$

${ }^{\mathrm{b}}$ Observed at well PK12 (close to BH-2)

Seawater Intrusion into the Aquifer Year 2001

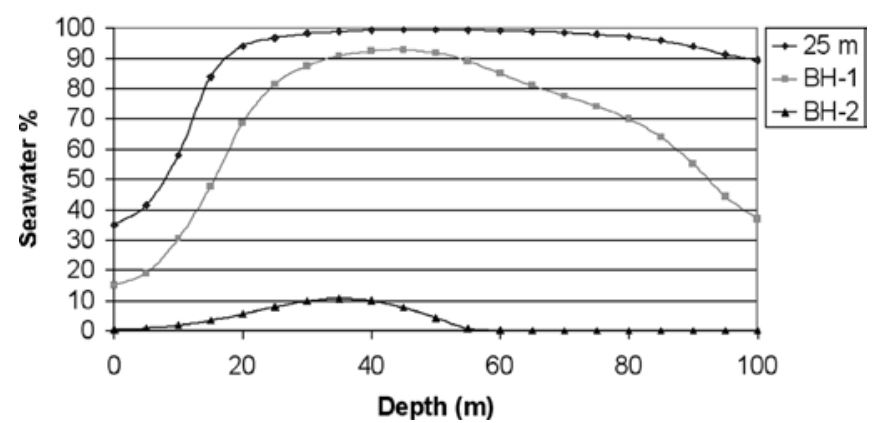

Fig. 6

Seawater intrusion into the aquifer in the year 2001 (at locations of $25 \mathrm{~m}$ from the shoreline, $\mathrm{BH}-1$ and $\mathrm{BH}-2$ wells)

aquifer started to lose water probably in the form of seepage and evaporation. This has caused the water levels to decline to the levels observed in 1990. This mechanism was simulated by the model, and the second phase of the calibration was based on this assumption. The model was calibrated to the observed values of the year 1990 accordingly. Calibration of the aquifer in this period has been accomplished by considering the effects of the water losses and by reflecting quarry production time as a run time in the model. Fig. 5 depicts behavior of the aquifer in the year 1990. Variation of the seawater percentage with respect to depth, at three different locations (at distance of $25 \mathrm{~m}$ from the shore, at $\mathrm{BH}-1$, and $\mathrm{BH}-2$ wells) are plotted on this figure. Comparison of the computed and the observed water levels supports the calibration study performed for this period (Table 2).

The third phase of the calibration study aims at simulating the behavior of the aquifer for the period 1990 through 2001. Starting from 1990 the calibration study continued further to estimate the water levels and the concentrations in the aquifer in 2001 (Fig. 6). Table 2 lists the water levels observed in the field and those computed by the model for different periods. This table and related figures (Figs. 7, 8) show that the computed and observed water levels and the concentrations at BH-coded wells are in very good agreement that verifies the success of the calibration. A correlation analysis performed between the observed and the

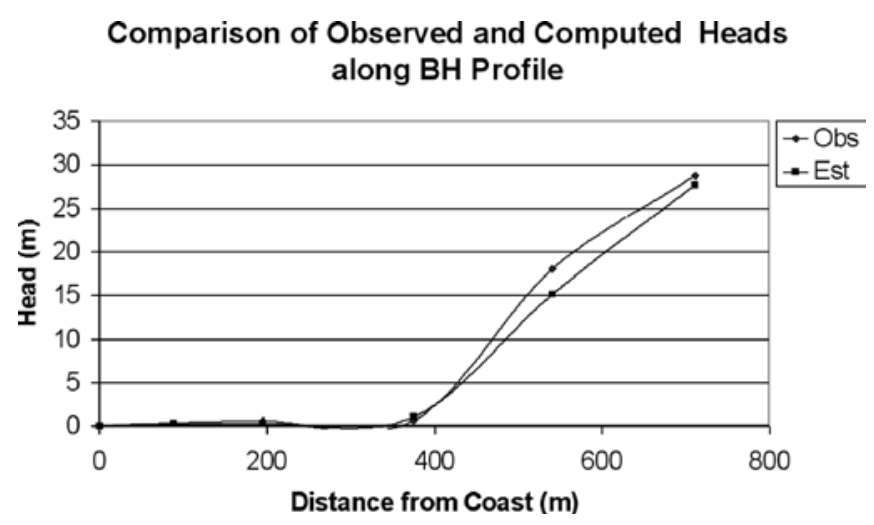

Fig. 7

Comparison of observed and estimated (computed) heads along $\mathrm{BH}$ profile

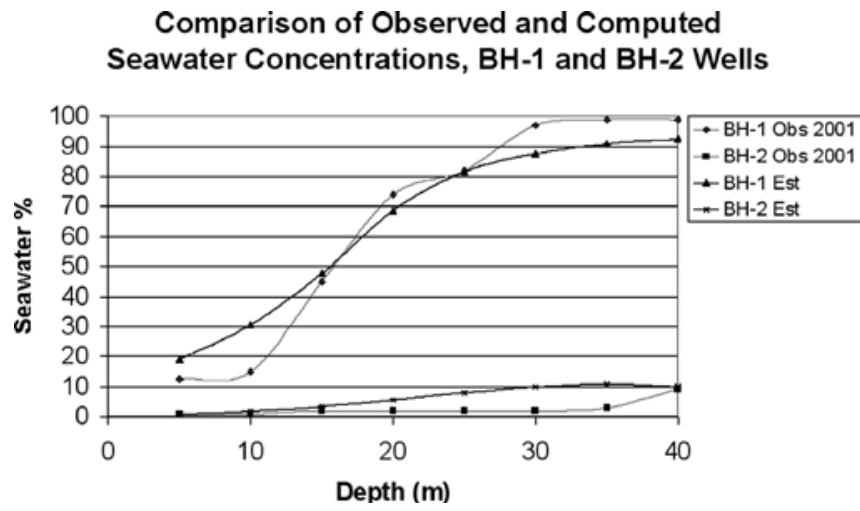

Fig. 8

Comparison of observed and estimated (computed) seawater concentrations at $\mathrm{BH}-1$ and $\mathrm{BH}-2$ wells

computed values of the variables, calculates correlation coefficients of 0.9972 (observed and computed water levels in August 2001) and 0.9934 (observed and computed seawater concentrations at BH-1 well in August 2001). In this way calibration of the finite element model has been successfully history-matched to the field conditions, and the model is made ready to be used for future predictions. During the calibration study, a wide range of physical and hydrogeochemical parameters have been tried and the most suitable parameters were obtained as a result of a 
Table 3

Physical and hydrogeochemical parameters used in the calibration
Fluid viscosity, $\mu_{\mathrm{f}}$

Fluid base density, $\rho_{\mathrm{f}}$

Molecular diffusivity of solid in fluid D

Porosity, $\eta$

Permeability, $\mathrm{k}$

Longitudinal dispersivity, $\alpha_{\mathrm{L}}$

Transverse dispersivity, $\alpha_{T}$
$0.001 \mathrm{~m}^{2} / \mathrm{s}$

$1,000 \mathrm{~kg} / \mathrm{m}^{3}$

$1.8571 \mathrm{E}-7 \mathrm{~m}^{2} / \mathrm{s}$

0.002

Varies within the range (1.0204 E-13-1.0204 E-15) $\mathrm{m}^{2}$ $10 \mathrm{~m}$

$1 \mathrm{~m}$

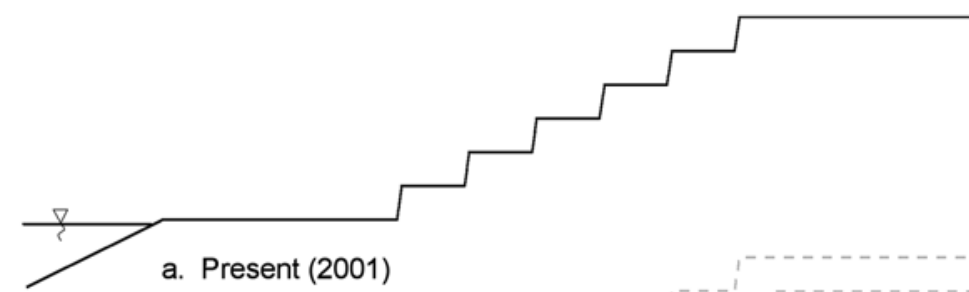

a. Present (2001)
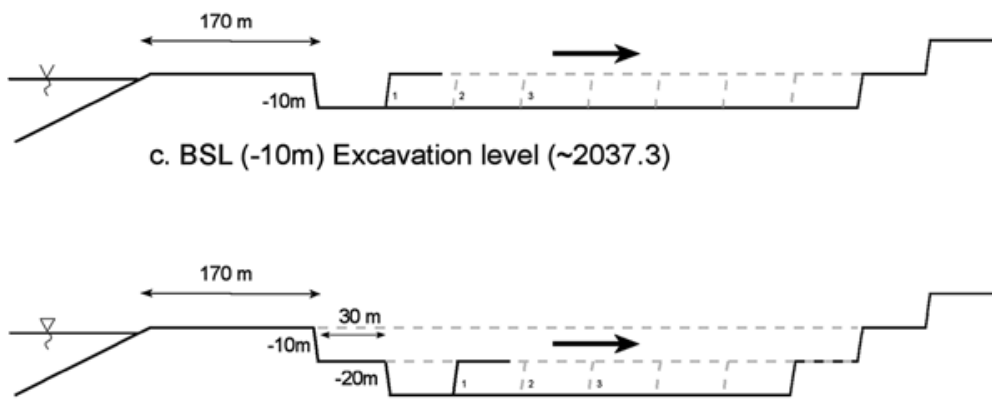

d. BSL (-20m) Excavation level ( 2041.5)

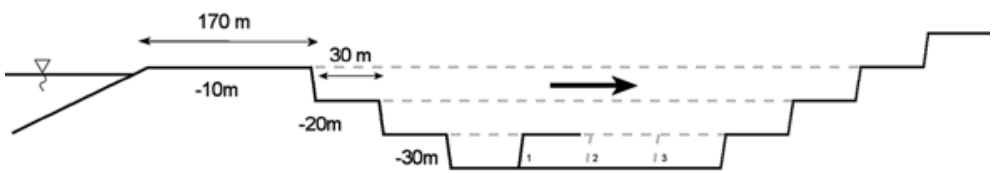

e. BSL (-30m) Excavation level ( 2044)

Fig. 9

Scenario I: a.s.l. production steps between 2001-2043 successful calibration (Table 3 ). Considering basal marl units in the region, the bottom of the model (bottom of the aquifer) is taken as $100 \mathrm{~m}$ below the sea level. Hydraulic conductivity of the aquifer ranges between $5 \times 10^{(-7)} \mathrm{m} / \mathrm{s}$ and $0.1 \times 10^{(-7)} \mathrm{m} / \mathrm{s}$ and the porosity is taken as constant, $0.002(0.2 \%)$. Molecular diffusion of salt is $1.8571 \times 10^{(-7)} \mathrm{m}^{2} / \mathrm{s}$ and the longitudinal and transverse dispersivities, $\alpha_{\mathrm{L}}$ and $\alpha_{\mathrm{T}}$ are 10 and $1 \mathrm{~m}$. The east end of the model is taken as a recharge boundary in terms of head variable and the bottom of the aquifer is a no flow boundary. Additionally, the concentrations are set to zero at the eastern boundary and they are equal to the concentration of seawater of any fluid entering the aquifer, at the western. The physical parameters of the aquifer and the boundary conditions have been used in the simulation studies.

\section{Modeling studies}

The calibrated model has been applied to the field in order to investigate the effects of b.s.l. and a.s.l. production in the quarry. Two alternative production scenarios have been considered and probable effects of a.s.l. and b.s.l. excavations on seawater intrusion into the aquifer have been studied. Future prediction studies are based on these two production scenarios that assume 43 years of total production period (30 years of a.s.l. and 13 years of b.s.l. production) in the quarry (Lafarge Kocaeli-Darıca Aslan Çimento, personal communication 2001). The first sce- 


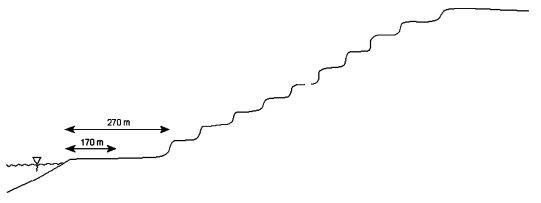

a.Mevcut durum

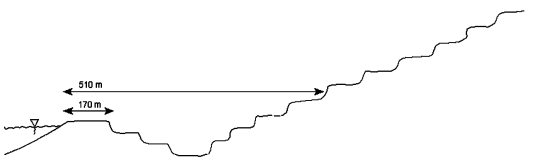

c. ASL+BSL end of step 2

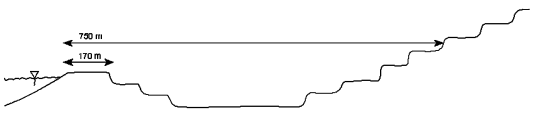

e.ASL+BSL end of step 4

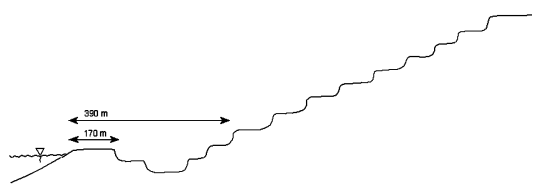

b.ASL+BSL end of step 1

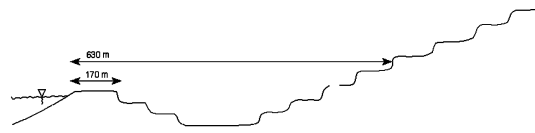

d.ASL+BSL end of step 3

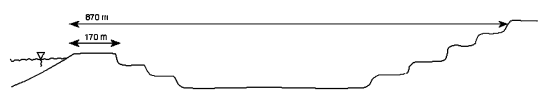

f. $A S L+B S L$ end of step 5

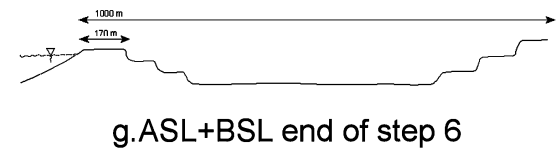

Fig. 10

Scenario II: a.s.l. and b.s.l. production steps 2001-2043

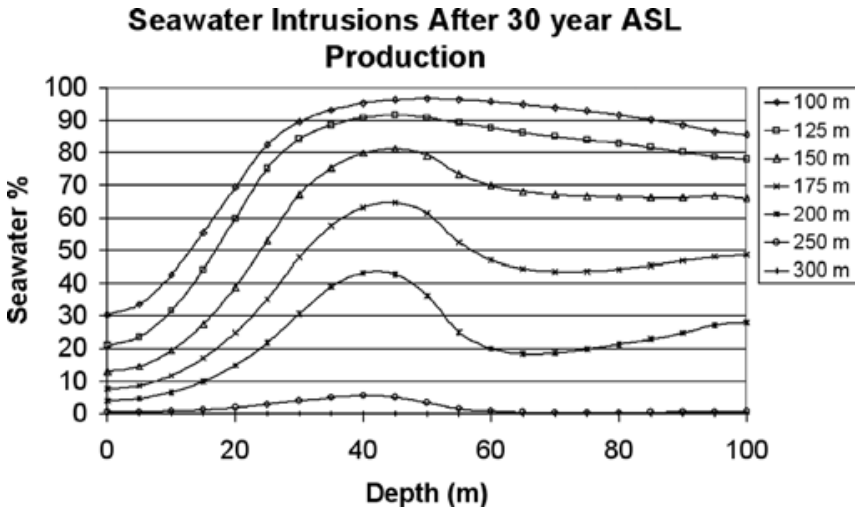

Fig. 11

Seawater intrusion into the aquifer after 30 year a.s.l. production (seawater concentrations along vertical profiles located at some distances from the shoreline)

nario, scenario I, assumes that starting from 2001, the next 30 years would be devoted only to a.s.l. and then the remaining 13 years would be used for b.s.l. production (Fig. 9). At the end of 30 years of a.s.l. production, the quarry would be a flat platform (altitude of +2 to $3 \mathrm{~m}$ ) and then b.s.l. would start opening the first excavation at a depth of $(-10 \mathrm{~m})$. The first b.s.l. level would then be followed by excavating to levels of $(-20 \mathrm{~m})$ and $(-30 \mathrm{~m})$ successively. Scenario II, on the other hand, assumes simultaneous operations both at a.s.l. and b.s.l. levels for the next 43 years after 2001 (Fig. 10). Transient simulation

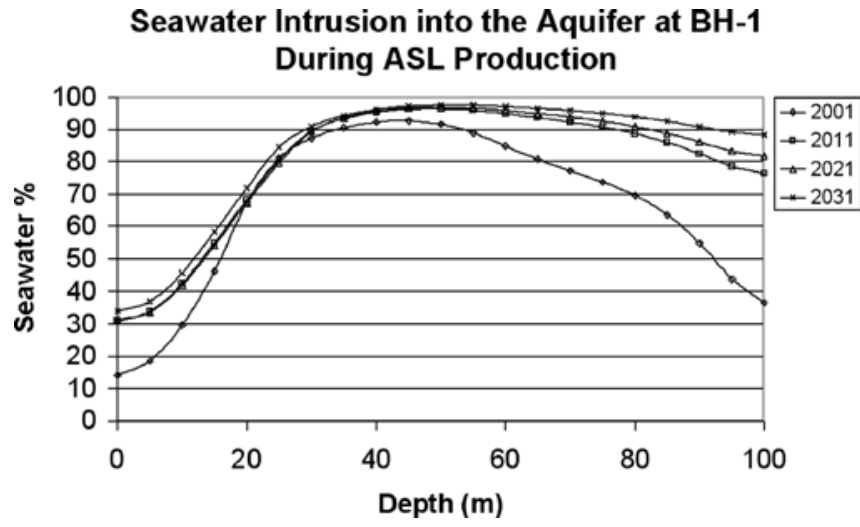

Fig. 12

Seawater intrusions into the aquifer at $\mathrm{BH}-1$ during a.s.l. production

and the related predictions for these scenarios have been accomplished by utilizing the calibrated numerical model.

\section{Scenario I: b.s.l. excavation following completion} of a.s.l. production

This scenario simulates completion of a.s.l. production in the next 30 years and then b.s.l. excavation would be initiated. In order to simulate this process the model is run for the next 30 years to simulate variation of water levels and advance of the intrusion mechanism in the aquifer. Behavior of the seawater intrusion in this period is given in Figs. 11, 12 and 13. Figure 11 shows change of seawater 


\section{Seawater Intrusion into the Aquifer at $\mathrm{BH}-2$} During ASL Production

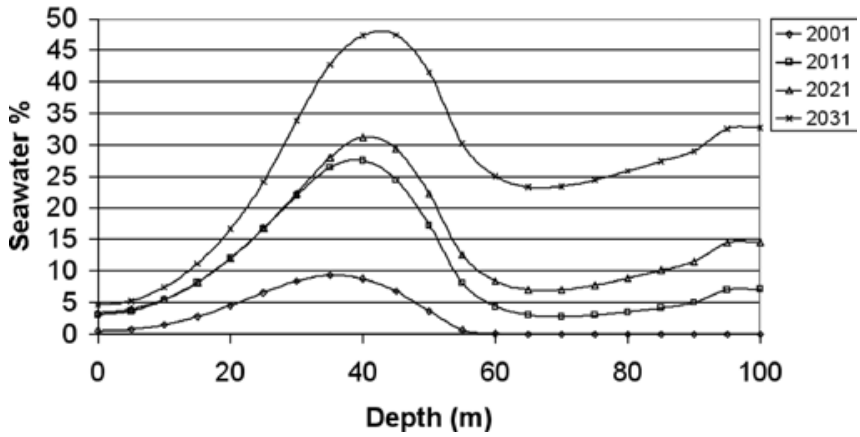

Fig. 13

Seawater intrusions into the aquifer at $\mathrm{BH}-2$ during a.s.l. production
Seawater Intrusion During BSL after 30 Year ASL (-20 m level)

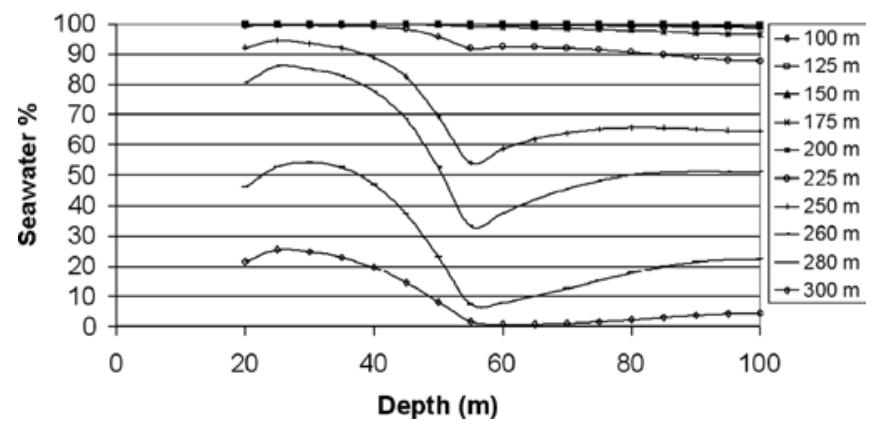

Fig. 15

Seawater intrusion during b.s.l. after 30 year a.s.l. $(-20 \mathrm{~m}$ level $)$
Seawater Intrusions During BSL after 30 Year ASL (-10 m level)

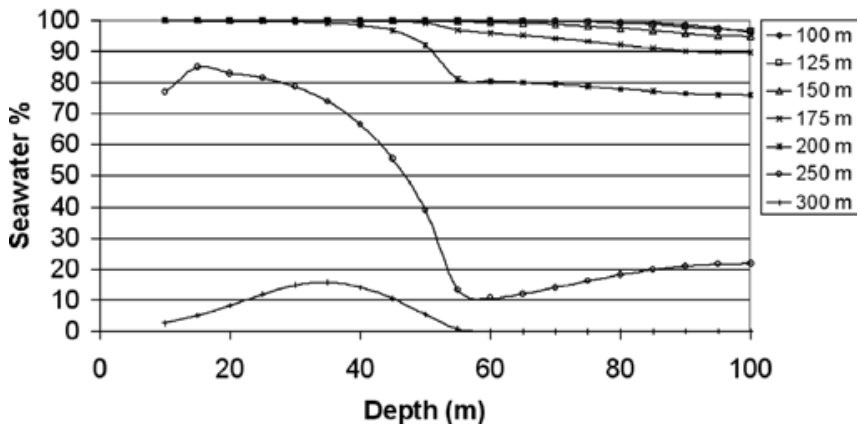

Fig. 14

Seawater intrusion during b.s.l. after 30 year a.s.l. (-10 m level)
Seawater Intrusion During BSL after 30 Year ASL (-30 m level)

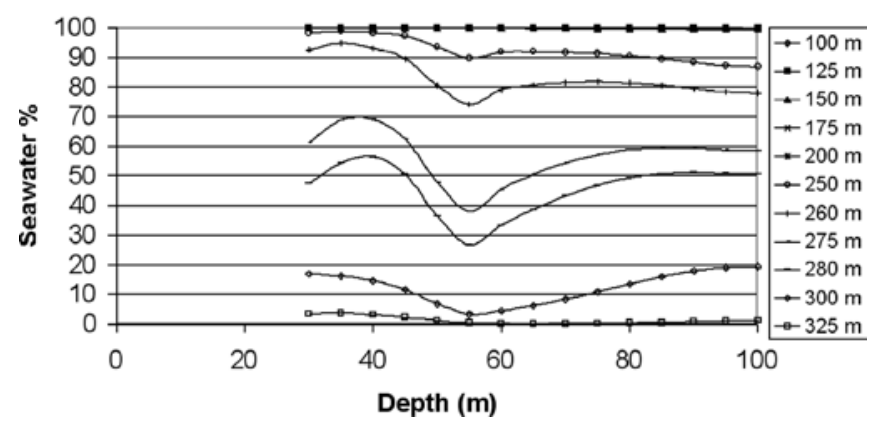

Fig. 16

Seawater intrusion during b.s.l. after 30 year a.s.l. (-30 m level)

to the project team. Effect of $(-10 \mathrm{~m})$ b.s.l. platform to the water levels and seawater percentages are given in Fig. 14. Model results show that seawater completely intrudes into the aquifer at $170 \mathrm{~m}$ profile, to the depth of $40 \mathrm{~m}$. In addition, seawater concentration, being only at $5 \%$ at the beginning of a.s.l., reaches to $80 \%$ at $250 \mathrm{~m}$ distance. At the end of first step (completion of $10 \mathrm{~m}$ b.s.l. level) seawater concentration is determined to be $18 \%$ at $40 \mathrm{~m}$ depth, at a distance of $300 \mathrm{~m}$.

After completion of the first b.s.l. platform, a $(-20 \mathrm{~m})$ platform is excavated leaving a $30-\mathrm{m}$ bench width. This platform is opened in the same way and the second b.s.l. platform at depth of $(-20 \mathrm{~m})$ is completed after 50 steps and within 1,550 days. Simulator results for the variables are given in Fig. 15, showing that the aquifer is completely intruded to a distance of $225 \mathrm{~m}$ inland at a depth of $40 \mathrm{~m}$. The same procedure is applied to open $(-30 \mathrm{~m})$ platform after the second platform is completed. b.s.l. $(-30 \mathrm{~m})$ level would take 895 days and when it is excavated all the profiles to depths of $100 \mathrm{~m}$ would completely be invaded to distances of $200 \mathrm{~m}$ inland (Fig. 16). A similar behavior is expected at depths of $40 \mathrm{~m}$ to distance of $250 \mathrm{~m}$. Seawater concentration decreases with distance and at $275 \mathrm{~m}$ distance it is estimated to be $75 \%$ and at $300 \mathrm{~m}$ it is $20 \%$. 
Seawater Intrusion After $120 \mathrm{~m}$ of Advance of ASL (2001-2008)

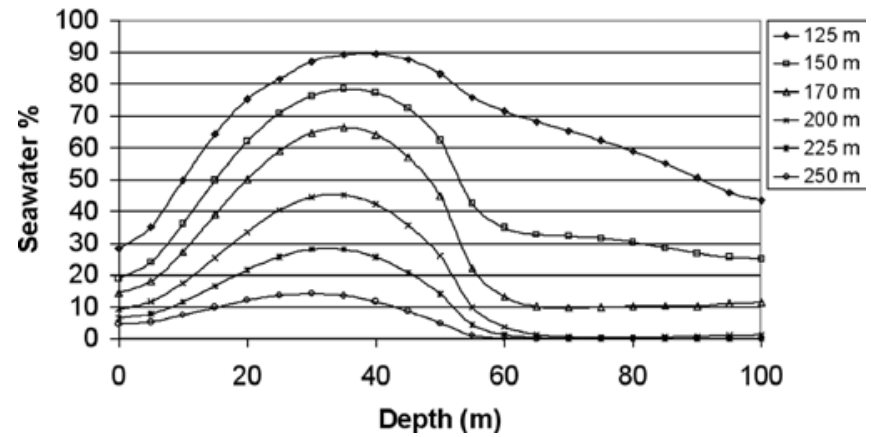

Fig. 17

Seawater intrusion after 120 m progress of a.s.l. (2001-2008)

Scenario II: a.s.l. and b.s.l. simultaneous production The second stage of the simulation is planned to model effects of simultaneous operations of the a.s.l. and b.s.l. productions. This scenario assumes excavations to be completed within the next 43 years (30 years for a.s.l. and 13 years for b.s.l.) following proposed production steps (Fig. 10). Such a production would require ASL levels to be advanced eastward to allow available volume before BSL excavations could be started. Considering these concepts Scenario II is planned to complete simultaneous a.s.l. and b.s.l. production in the quarry.

In order to implement Scenario II, the simulator is run for a period corresponding to $120 \mathrm{~m}$ advance of a.s.l. benches and the water levels and concentrations are computed (Fig. 17). The figure shows that observed seawater percentage at BH-2 (8\% at $40 \mathrm{~m}$ depth in 2001) would be increased above $50 \%$ at the same depth. On the other hand it is estimated to have seawater percentage at $28 \%$ level at $10 \mathrm{~m}$ depth and $50 \%$ at $20 \mathrm{~m}$ depth, if an excavation would be opened at a distance of $170 \mathrm{~m}$. Seawater percentages are more than these values at the same depths and they decrease with increased distance from the coast. Considering these, $170 \mathrm{~m}$ distance for a proposed excavation is found to be quite reasonable.

In the first step of Scenario II, simulation of $120 \mathrm{~m}$ advance of a.s.l. benches have been accomplished and then the excavation opened in 2001 was enlarged $270 \mathrm{~m}$ for $(-10 \mathrm{~m})$ level and the first $(-20 \mathrm{~m})$ excavation was opened at a width of $130 \mathrm{~m}$. Results of the simulation performed for these operations, which would take approximately 10 years, are given in Fig. 18. It is computed that all the profiles (at $40 \mathrm{~m}$ depth) at $225 \mathrm{~m}$ inland, would be completely intruded by seawater, and seawater percentage decreases with distance to $70 \%$ at $250 \mathrm{~m}$, and $30 \%$ at $275 \mathrm{~m}$. This is followed by the second step and a.s.l. benches, $(-10 \mathrm{~m})$ and $(-20 \mathrm{~m})$ levels advanced $120 \mathrm{~m}$ eastward and then the first $(-30 \mathrm{~m})$ level was excavated. This step also would take 10 years, and the results of this operation would cause the concentrations to advance landward. The operations in the third, fourth, fifth and the sixth steps of simulation are considered as taking 8, 7, 6 and 5 years and therefore related simulations are
ASL+BSL Excavation End of 1st Step

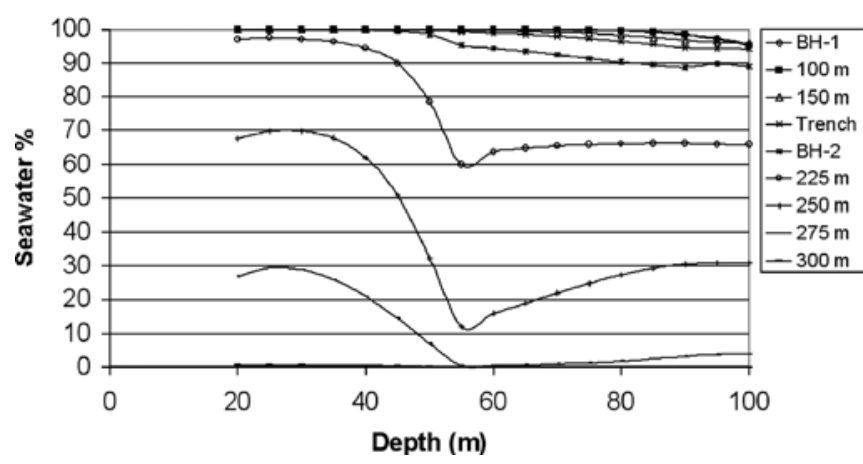

Fig. 18

Seawater intrusions at the end of 1 st step in a.s.l. + b.s.l. production

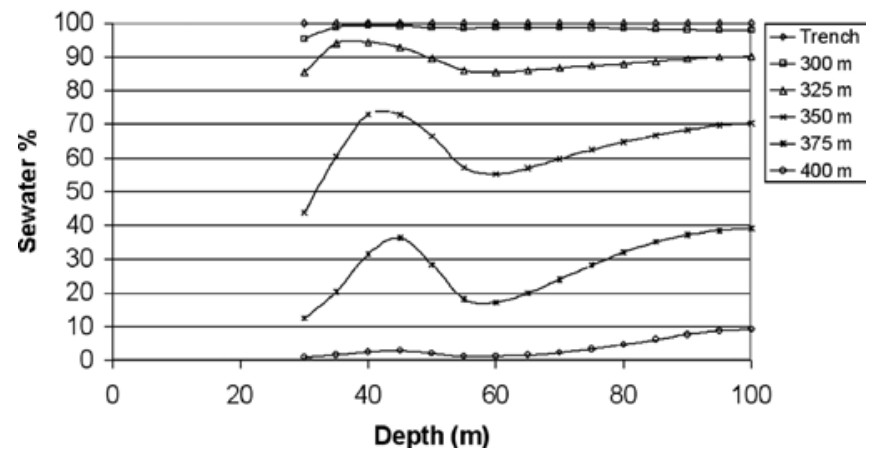

Fig. 19

Seawater intrusions at the end of sixth step in a.s.l. + b.s.l. production

performed accordingly. Figure 19 shows the simulation results obtained at the end of the sixth step, which indicates that more than $90 \%$ concentrations would be expected within $325 \mathrm{~m}$ and seawater concentration would be very low (about $4 \%$ ) at distance of $400 \mathrm{~m}$ inland. It is also obvious that landward progress of a.s.l. +b.s.l. excavation promotes the advance of the seawater front.

\section{Conclusions}

The following conclusions are obtained from the simulation study:

1. The proposed model has been formulated by using historical behavior of the aquifer and it has been successfully calibrated by the observations made during the project work. Calibration studies were started from the virgin conditions of the aquifer and the equilibrium conditions were taken as the initial conditions and the historical behavior of the aquifer from the virgin stateto-present was simulated to complete history matching of the variables. Correlation analysis, made between the observed and the model-computed values of the vari- 
ables, computed very high correlation coecients ( 0.9972 for water levels, 0.9935 for concentrations). This emphasizes that selection of the physical parameters and the boundary conditions is quite appropriate and the calibrated model reliably simulates the future behavior of the aquifer.

2. The calibrated model has been applied to investigate the eects of b.s.l. excavations on the seawater intrusion into the aquifer. Two alternative scenarios have been designed in order to simulate the future operations to be performed during b.s.l. excavations. These scenarios are so planned that they would reflect the b.s.l. operations in a more realistic manner since these operations play a very important role in the success of the model. For this reason future b.s.l. excavations are simulated using the average production rate of the quarry and allowing enough process time for the model to accomplish the simulation.

3. The proposed study assumed that excavation operation in both scenarios should be started at a location, which is $170 \mathrm{~m}$ inland, although the other profiles have been thoroughly evaluated. It is clear that seawater intrusion would become less towards inland; however, this would cause reduction in the amount of raw material that could be produced from the quarry. On the other hand locations closer to the sea would be under seawater intrusion risk. Considering these facts it is concluded that $170 \mathrm{~m}$ distance would be a good choice to start future b.s.l. excavations.

4. Scenario I requires a.s.l. production to be completed within the next 30 years to start b.s.l. excavations. The first excavation is to be opened at $170 \mathrm{~m}$ inland and be enlarged to complete $(-10 \mathrm{~m})$ b.s.l. level. This comprises the first step in Scenario I and estimated to take about 2,300 days (6.3 years). This has been modeled accordingly in the simulator and it is completed at the end of 53 simulation runs. After forming $(-10 \mathrm{~m})$ platform, seawater concentration of $18 \%$ is expected at a depth of $40 \mathrm{~m}$ at a distance of $300 \mathrm{~m}$ from the shoreline. When $-20 \mathrm{~m}$ platform is formed the aquifer is highly aected from seawater intrusion to a distance $225 \mathrm{~m}$ inland at a depth of $40 \mathrm{~m}$. After $-30 \mathrm{~m}$ platform $75 \%$ seawater concentration is expected at a distance of $275 \mathrm{~m}$, and $20 \%$ at $300 \mathrm{~m}$.

5. The second scenario is designed to produce both ASL and BSL levels simultaneously in the next 43 years. In the proposed study this is thought to be completed at the end of 6 consecutive steps, that would take 10, 10, 8, 6,5 , and 4 years, respectively. On the other hand, present conditions in the quarry would not allow enough volume to excavate if b.s.l. starts immediately at $170 \mathrm{~m}$ inland location. For this reason the production design is modified slightly and a waiting period of about 7.5 years is allowed before advance of ASL benches $120 \mathrm{~m}$ eastward.

6. In scenario II when $-20 \mathrm{~m}$ depth is reached seawater concentrations of $70 \%$ at distance of $250 \mathrm{~m}$, and $30 \%$ at $275 \mathrm{~m}$ are expected at $-40 \mathrm{~m}$ depth. After reaching to $30 \mathrm{~m}$ the seawater concentration increases up to $85 \%$ at $275 \mathrm{~m}$ and $50 \%$ at $325 \mathrm{~m}$. However, at a distance of
$400 \mathrm{~m}$, the concentration is around $4 \%$. Both scenarios show that the seawater may intrude to a distance of less than about $350 \mathrm{~m}$ inland from the shoreline.

7. During b.s.l. mining the amount of water to be discharged from the pit ranges between 50 and 10 tons/day for both scenarios. These indicate that easily manageable quantities of water would be discharged during b.s.l. mining.

Acknowledgement The authors greatly appreciate the financial, logistical and technical support provided by the Kocaeli-Darica Lafarge Aslan Cement Company. The authors would also like to thank to Dr. Z. Camur, Dr. T. Topal, Dr. M.L. Suzen and Mr. E. Yesilnacar for their invaluable collaboration during field studies.

\section{References}

Bear J, Dagan G (1964) Moving interface in coastal aquifers. J Hydraul Div Am Soc Civil Eng 99 (HY4):193-216

Croucher AE, O'Sullivan MJ (1995) The Henry problem for saltwater intrusion. Water Resources Research 31 (7):1809-1814

Doyuran V, Karahanoğlu N, Çamur Z, Topal, T, Süzen ML, Yeşilnacar E (2001) Hydrogeological and hydrochemical investigation and exploitation plan for BSL mining of Kocaeli-Darıca Lafarge Aslan Cement raw material site, Project Report, METU, Ankara, Turkey, 90 pp

Emekli N, Karahanoğlu N, Doyuran V, Yazıcıgil, H (1996) Numerical simulation of saltwater intrusion in a groundwater basin. Water Environ Res 68 (5):855-866

Erguvanlı K, Yüzer E, Güleç K, Zambak C (1972) Geology of the raw material site, Darıca-Aslan cement factory (in Turkish). Istanbul Technical University Turkey

Frind EO (1982) Simulation of long-term transient densitydependent transport in groundwater. Adv Water Resour 5:73-97 GEMMES (1997) Hydrogeological study for exploitation undersea level in the Aslan Quarry, Final Report, Tredi Division Gemmes, $10 \mathrm{pp}$

Gültekin A (1983) An investigation for cement raw material in the Kocaeli Peninsula region (in Turkish). MTA, 146 pp

Huyakorn PS, Wu YS, Park NS (1996) Multiple approach to the numerical solution of a sharp interface saltwater intrusion problem. Water Resour Res 32 (1):93-102

MTA (1991) Hydrogeological investigation in the raw material site of Kocaeli-Darıca Aslan cement factory (in Turkish). MTA, $25 \mathrm{pp}$

Reilly TE, Goodman A (1985) Quantitative analysis saltwaterfreshwater relationships in groundwater systems, a historical perspective. JHydrol 80:125-160

Sadeg SA, Karahanoğlu N (2001) Numerical assessment of seawater intrusion in the Tripoli region, Libya. Environ Geol 40:1151-1168

Shamir U, Dagan G (1971) Motion of seawater interface in coastal aquifers; a numerical solution. Water Resour Res 7(3):644-657

Voss C (1984) SUTRA, a finite element simulation model for saturated-unsaturated, fluid density dependent groundwater flow with energy transport or chemically reactive single species solute transport. USGS Water Resources Investigations Report 84-4369

Voss C, Anderson J (1993) Regional flow in the Baltic Shield during Holocene coastal regression. Ground Water 31(6):9891006

Yeraltı Aramacilık (1994) Geophysical investigation in the Darıca Aslan cement quarry 